\title{
Stacking and Analysis of Melamine in Milk Products with Acetonitrile-Salt Stacking Technique in Capillary Electrophoresis
}

\author{
Yu Kong, ${ }_{1}^{1}$ Chong Wei, ${ }^{2}$ Zhanwu Hou, ${ }^{1}$ Zilong Wang, ${ }^{1}$ Jiaqiang Yuan, \\ Jiang Yu, ${ }^{1}$ Yongxi Zhao, ${ }^{1}$ Yuhai Tang, ${ }^{1}$ and Meili Gao ${ }^{1}$ \\ ${ }^{1}$ Institute of Mitochondrial Biology and Medicine, The Key Laboratory of Biomedical Information Engineering of Ministry of Education, \\ Department of Bioengineering, School of Life Science and Technology, Xian Jiaotong University, Xian 710049, China \\ ${ }^{2}$ Department of Criminal and Inspectoral, Public Security Bureau of Han Zhong City, Shaanxi, China
}

Correspondence should be addressed to Meili Gao; gaomeili@mail.xjtu.edu.cn

Received 28 June 2014; Accepted 22 July 2014; Published 18 August 2014

Academic Editor: Josep Esteve-Romero

Copyright (c) $2014 \mathrm{Yu}$ Kong et al. This is an open access article distributed under the Creative Commons Attribution License, which permits unrestricted use, distribution, and reproduction in any medium, provided the original work is properly cited.

\begin{abstract}
Melamine was measured in real milk products with capillary electrophoresis (CE) based on acetonitrile-salt stacking (ASS) method. Real milk samples were deproteinized with acetonitrile at a final concentration of $60 \%(\mathrm{v} / \mathrm{v})$ and then injected hydrodynamically at $50 \mathrm{mBar}$ for $40.0 \mathrm{~s}$. The optimized buffer contains $80.0 \mathrm{mmol} / \mathrm{L} \mathrm{pH} 2.8$ phosphates. Melamine could be detected within $20.0 \mathrm{~min}$ at $+10 \mathrm{kV}$ with a low limit of detection (LOD) of $0.03 \mu \mathrm{mol} / \mathrm{L}$. Satisfactory reproducibility (inter- and intraday RSD\% both for migration time and peak area was lower than 5.0\%) and a wide linearity range of $0.05 \mu \mathrm{mol} / \mathrm{L} \sim 10.0 \mu \mathrm{mol} / \mathrm{L}$ were achieved. The proposed method was suitable for routine assay of MEL in real milk samples that was subjected to a simple treatment step.
\end{abstract}

\section{Introduction}

Melamine (MEL) in animal foods and milk products had caused serious accidents, as its metabolism, melamine cyanurate, was easily crystallized in organs and was tending to cause kidney stone and damage [1-3]. Therefore, establishing a powerful rapid sensitive analytical method for measuring low concentration of MEL in kinds of milk products would benefit the routine assay of the related products.

Several analytical methods, such as gas chromatographymass spectrometry (GC-MS) [4], high performance liquid chromatography (HPLC) [5-7] gold nanoparticles [8], colloidal selenium immunoassay [9], and Terahertz timedomain spectroscopy [10] had been reported. However, many methods depended on complicated sample treatments. As in GC-MS methods, the sample derivation was strongly demanded as MEL contains special label group [4]; as in HPLC methods, liquid-liquid, liquid-solid extraction procedure was needed to cleanse the sample and perform better separation results. In some cases, in order to lower the limit of detection (LOD) or obtain detailed information of the analytes, special detectors, such as mass spectrum (MS) [5], fluorescence detection [6], surface enhanced raman scattering [8], electrochemical approach [11], and online solid-phase extraction [7], were also used. However, some of these detectors were uncommon or had special demands. For example, in MS detecting methods, salt-free samples were required.

Capillary electrophoresis had advantages on separating complicated samples and had been applied to determine MEL [12-14]. Moreover, CE online stacking methods, which could easily perform enrichment of low-concentration analytes and achieved lower LODs, had also been used for assay of MEL in real samples [15-19]. Jin et al. [16] proposed several stacking methods, such as including large-volume sample stackingsweeping and selective exhaustive injection-sweeping (SEI$S$, in either cation or anion mode), for determination of melamine and its derivatives in liquid milk. LOD of MEL was around $0.01 \mathrm{ng} / \mathrm{mL}$, however, it's difficult to achieve better sensitivities for all derivatives in one mode. Li et al. 
[17] combined cation selective exhaustive injection (CSEI) with sweeping-MEKC method. In their study, the LOD was $23.4 \mathrm{pg} / \mathrm{mL}$ for MEL; however, the recovery of MEL was unsatisfied (ca. 74-83\%). Wu et al. [18] developed a MEKC sweeping method for MEL, face-centred cube central composite design was used for optimization of conditions, and the LOD of MEL could reach $5 \mathrm{ng} / \mathrm{mL}$ with satisfied recovery within $13 \mathrm{~min}$.

In our works, acetonitrile-salt stacking (ASS) [20-25] was used for detecting MEL under cation mode in milk products. The factors that influenced both stacking and separation, such as buffer $\mathrm{pH}$, sample acetonitrile concentration, sample salt concentration, injection time, buffer concentration, stacking and separation voltage, were carefully investigated and optimized.

\section{Experimental}

2.1. Chemicals. Melamine was purchased from Sigma (St. Louis, MO, USA). Phosphoric acid, sodium dihydrogen phosphate, disodium hydrogen phosphate, sodium phosphate, sodium chloride, and acetonitrile (HPLC-grade agents) were purchased from Tianjin chemical reagent company (Tianjin, China). Water used throughout was purified by OLST M6 (Ao Lian Co, Xian, China) with a conductivity of $18.2 \Omega \cdot \mathrm{cm}$ and all the solutions and samples were made daily and filtered through $0.22 \mu \mathrm{m}$ filter.

2.2. Instrumentation. Experiments were performed on Agilent 3D CE Capillary electrophoresis system (Agilent, USA) equipped with a diode array detector (DAD) and a temperature controller $\left(15 \sim 60 \pm 0.1^{\circ} \mathrm{C}\right)$. Instrument control and data analysis were carried out by Agilent Chem station (Rev.A.09.03, Agilent, USA) on a personal computer. For pH measurements, a pH meter (PB-10, Sartorius, Germany) calibrated with a precision of $0.01 \mathrm{pH}$ unit was employed. Centrifugation was performed on a 5810R (Eppendorf, Germany). All the CE experiments were performed on a fused silica capillary (Yongnian photoconductive fibre factory, Hebei, China).

2.3. Preparation of Milk Samples and Standard Samples. The milk samples, obtained from local markets, were deproteinized with acetonitrile at the rate of 6:4 (acetonitrile: milk, v/v) or as specified. Then, the treated samples were centrifuged for $15 \mathrm{~min}$ at 14,200 rpm to eliminate the precipitates. All supernatants were assayed after being added with $100 \mathrm{mmol} / \mathrm{L} \mathrm{NaCl}$ and filtration.

Standard stock solutions of melamine $(8 \mathrm{mmol} / \mathrm{L})$ were prepared quantitatively with water and stored at $4^{\circ} \mathrm{C}$ until usage. All working standard samples contained $8 \mathrm{mmol} / \mathrm{L}$ phosphate buffer and required concentration of sodium chloride and $60 \%$ acetonitrile (or as specified) and $\sim 10 \mu \mathrm{mol} / \mathrm{L}$ MEL (final concentration).

2.4. Electrophoresis Procedure. All the separations were performed on a fused-silica capillary $(75 \mu \mathrm{m}$ I.D., effective length of $39 \mathrm{~cm}$, and total length of $50 \mathrm{~cm}$ ) at $20^{\circ} \mathrm{C}$ with a constant

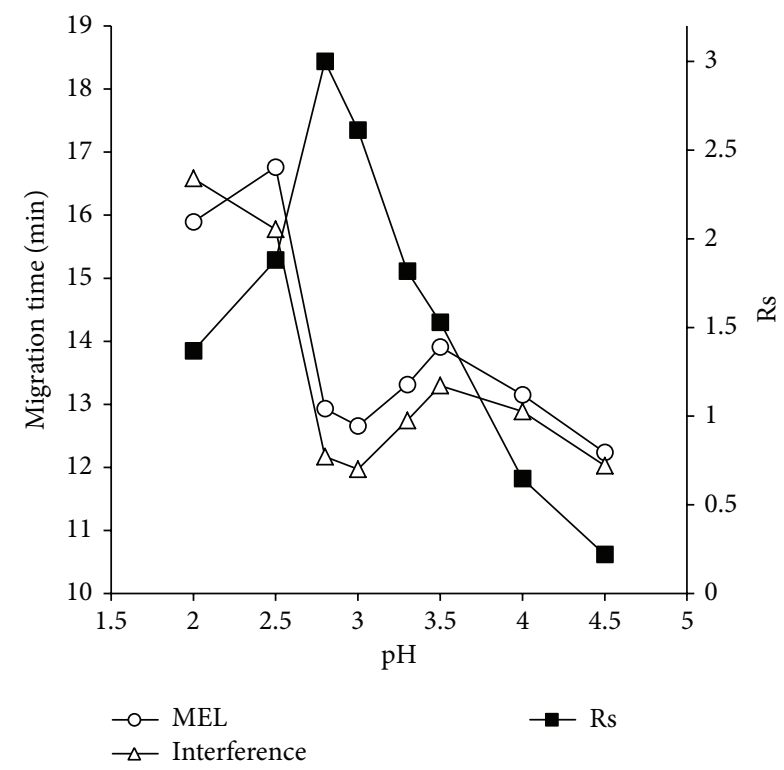

FIGURE 1: Influence of $\mathrm{pH}$ on migration times and Rs values.

separation voltage of $+10.0 \mathrm{kV}$. For the first usage, the capillary was activated with $1.0 \mathrm{~mol} / \mathrm{L} \mathrm{NaOH}$ for 1 hour. The stacking and separation buffer consisted of $80 \mathrm{mmol} / \mathrm{L}$ phosphate buffer ( $\mathrm{pH}$ 2.8). The samples were injected hydrodynamically at $+50 \mathrm{mBar}$ for $40.0 \mathrm{~s}$ (about $20 \%$ of the capillary efficient length) or as specified. Before each run, the capillary was rinsed with $0.1 \mathrm{~mol} / \mathrm{L} \mathrm{NaOH}$ for $3 \mathrm{~min}$ at $1.4 \times 10^{3} \mathrm{mBar}$.

\section{Results and Discussion}

As the ASS method stacked samples via transient pseudoisotachophoresis way and separated samples via capillary zone electrophoresis mode, several factors that affected stacking, such as sample matrix, voltage, injection time, and separation, such as buffer $\mathrm{pH}$, were carefully studied. In general, MEL was positively charged under the selected condition. It was stacked based on its difference of migrating velocity between sample zone (faster) and outlet buffer zone (slower).

3.1. Influence of Buffer $p H$ and Concentration on Separation. Buffer $\mathrm{pH}$ was one of most important factors that would influence separation and stacking. In this section, a $\mathrm{pH}$ range of 2.0 5.0 was firstly studied, as the pKa values of MEL were about 5.0; it could only be positively charged when buffer $\mathrm{pH}$ was lower than 5.0. There was an interferent compound in blank milk sample (contained no MEL, data not shown) which had similar migration time as MEL. Regarding this, the optimization of $\mathrm{pH}$ was mainly based on the resolution (Rs) between MEL and interferent as well as their migration times. The influence of $\mathrm{pH}$ on $\mathrm{Rs}$ and migration times were shown in Figure 1. It indicated that, at the lower $\mathrm{pH}(<2.5)$, the electroosmotic flow (EOF) was nearly zero, and MEL was strongly and positively charged and migrated to the detecting window by itself; when the $\mathrm{pH}$ became higher, the silanol started to dissociate and, as a result, the EOF slightly 


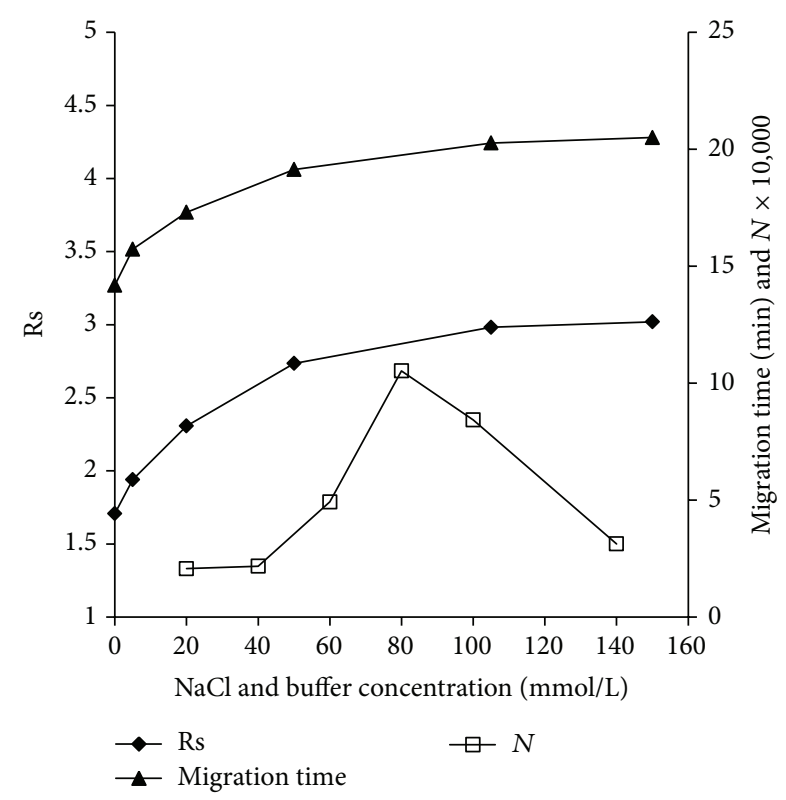

FIGURE 2: Influence of buffer concentrations on theoretical plate numbers, influences of $\mathrm{NaCl}$ concentration on Rs and migration times.

increased and migration times dropped; $\mathrm{pH} 3.5$ had the slight longer migration time compared with $\mathrm{pH} 3.0$, which may be caused by the faster decreasement of effective positive charges of MEL compared with the slower increasement of EOF. In addition, a peak order change was also observed in $\mathrm{pH}$ range of 2.0 2.5, which was similar to our CZE separation works (data not shown). Finally, based on the curve of Rs in Figure 1, $\mathrm{pH} 2.8$, which had the best Rs value and relative shorter migration time, was chosen for further usage.

The influence of buffer concentration, ranged from $20.0 \mathrm{mmol} / \mathrm{L}$ to $140.0 \mathrm{mmol} / \mathrm{L}$, on stacking was investigated (Figure 2). Theoretically, to some extent, higher buffer concentration provided larger conductivity difference between buffer and sample zone, which in turn might perform better primary stacking effect. In our works, stacking could not take place at the low buffer concentration $(<40 \mathrm{mmol} / \mathrm{L})$, as the conductance of the buffer was similar to that of the sample zone, the difference of migrating velocity of the MEL in buffer and in sample zone was not large enough to initiate stacking. When buffer concentration was higher than $40.0 \mathrm{mmol} / \mathrm{L}$, stacking phenomena occurred. As the buffer concentration increased, the theoretical plate number $(N)$ increased firstly followed by decreasing when the concentration was higher than $80.0 \mathrm{mmol} / \mathrm{L}$, which may heat due to the broaden effects of extra Joule. Finally, a concentration of $80.0 \mathrm{mmol} / \mathrm{L}$ was selected for further studies.

3.2. Influence of Sample Matrix. The effect of the acetonitrile concentration in sample on stacking was studied and optimized as organic reagent acted as accelerator for speeding up the velocities of analytes [15]. It could be seen (Figure 3), as the percent of the acetonitrile was lower than $50 \%$, that the baseline around MEL became unsatisfied (arrow pointed

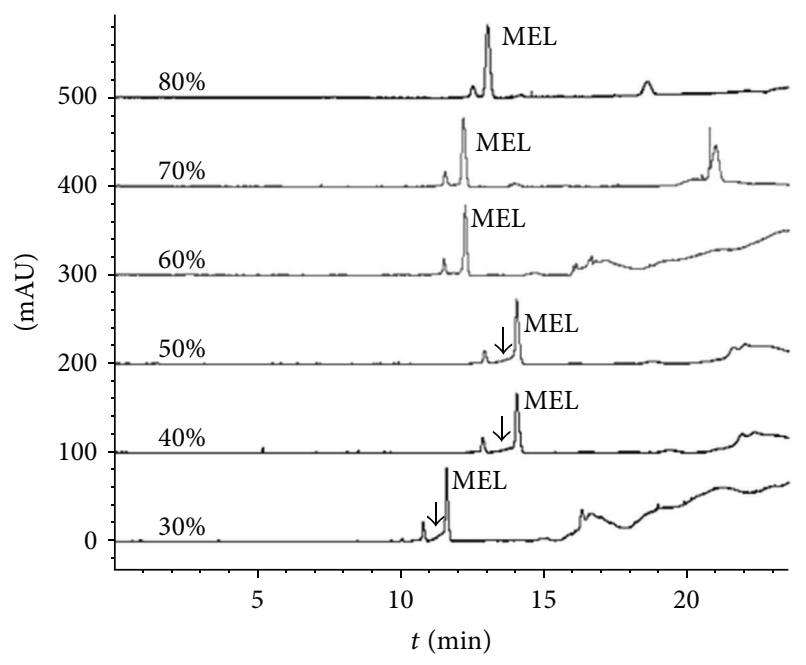

FIGURE 3: Electropherograms of milk treated with different percentages of acetonitrile. Condition: samples were treated with different percentages of acetonitrile (v/v) and were injected hydrodynamically at $50 \mathrm{mBar}$ for $50 \mathrm{~s}$. All samples contain $10 \mathrm{mmol} / \mathrm{L} \mathrm{NaCl}$ and $8 \mathrm{mmol} / \mathrm{L} \mathrm{pH} 2.8$ phosphate solution and $3 \mu \mathrm{mol} / \mathrm{L}$ MEL.

in Figure 3) for separation and quantification, although the Rs value was higher enough between the interferent and MEL (Rs > 3.5). When the percentage was larger than $50 \%$, baseline separation and stacking were both achieved. Meanwhile, the Rs decreased from 3.27 (60\%) to 1.53 (80\%) as the percentage of acetonitrile increased. Therefore, a percentage of $60 \%$ was considered as the better condition that provided less sample dilution and better Rs.

$\mathrm{NaCl}$ concentration was also an important factor that affected stacking, as the $\mathrm{Na}^{+}$acted as leading ions in ASS procedure. Normally, almost all milk products contained $\mathrm{Na}^{+}$, and the $\left[\mathrm{Na}^{+}\right]$varied in larger range (from $0.18 \%$ to $1.5 \%$ in mass/volume form or in another form, $3 \sim 25 \mathrm{mmol} / \mathrm{L}$ ). In this section, same real sample was added with different amount of $\mathrm{NaCl}$ (in range of $0 \sim 150 \mathrm{mmol} / \mathrm{L}$ ) and was tested under same condition. The influences of $\mathrm{NaCl}$ concentration on Rs and migration times were shown in Figure 2. As the $\mathrm{NaCl}$ concentration increased, the migration time and Rs increased correspondingly (Rs ranged from 1.7 to 3.0, while migration times ranged from $14.2 \mathrm{~min}$ to $20.5 \mathrm{~min}$ ) until the concentration of $\mathrm{NaCl}$ was higher than $100 \mathrm{mmol} / \mathrm{L}$; the similar stacking and separation results were obtained. All these indicated that the method had a good tolerance on various concentrations of $\mathrm{NaCl}$, which made it more suitable for assaying kinds of milk products. Finally, to keep the migration times similar, in the later assays, $100 \mathrm{mmol} / \mathrm{L}$ $\mathrm{NaCl}$ was added to the treated real milk samples before measurements.

3.3. Selection of Injection Times. As the injection time (presented as percent of the efficient length) was closely related to sensitivity of the method, the maximum injection time was carefully selected in this section. Figure 4 showed that migration times increased (as a result of decreasing EOF) while the 


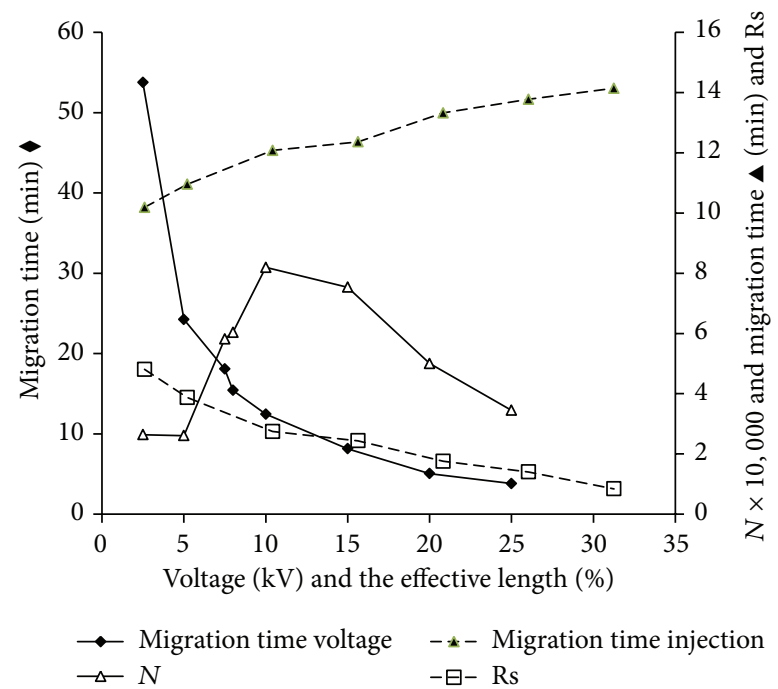

FIGURE 4: Influences of injection volume on migration times and Rs, effects of voltages on stacking.

Rs values decreased (mainly caused by the decreasing efficient capillary length) with increasing injection times (similar to the results of Gao's work [25]). Based on the Rs value between MEL and interferent, $20 \%$ of the efficient capillary length $(50 \mathrm{mBar} \times 40.0 \mathrm{~s})$ was considered as a best injection percent $(\mathrm{Rs}=1.75)$.

3.4. Effect of Stacking Voltage. In this section, stacking voltage was investigated in detail (Figure 4). It could be seen that $N$ value appeared as a bell-shaped curve while the voltage increased from $2.5 \mathrm{kV}$ to $25.0 \mathrm{kV}$. And the migration times decreased as the voltage increased. Experimental data showed that neither under lower nor higher voltage could MEL be well stacked. A voltage of $+10.0 \mathrm{kV}$ (ground at outlet) was finally decided to be the best condition as it was relatively less time-consuming and of highest $N$ value $(82,000)$.

3.5. Additional Rinsing Step. As the status of the inner-wall silanol greatly affected reproducibility of the method, special rinsing step was added before each run. It could be seen in Figure 5 that an additional $0.1 \mathrm{mmol} / \mathrm{L} \mathrm{NaOH}$ rinsing step was crucial for maintaining reproducibility. Without $\mathrm{NaOH}$ rinsing step (capillary was only flushed with water and running buffer for $1.0 \mathrm{~min}$ and $3.0 \mathrm{~min}$ respectively, Figure 5(B)), the separation and stacking were ruined compared with the first run (Figure 5-(A)). When the $\mathrm{NaOH}$ rinsing step was added before the next assay, better separation and stacking regained (Figure 5-(C)). For the selection of the $\mathrm{NaOH}$ rinsing time, our data proved that the $0.1 \mathrm{mmol} / \mathrm{L}$ $\mathrm{NaOH}$ rinsing time should be at least $3.0 \mathrm{~min}$ in order to achieve satisfied reproducibility.

3.6. Validation of the Method. Under the optimized condition, MEL could be easily detected within $20.0 \mathrm{~min}$. Six replicates of the samples were used to test the inter- and intraday reproducibility of the method both for migration

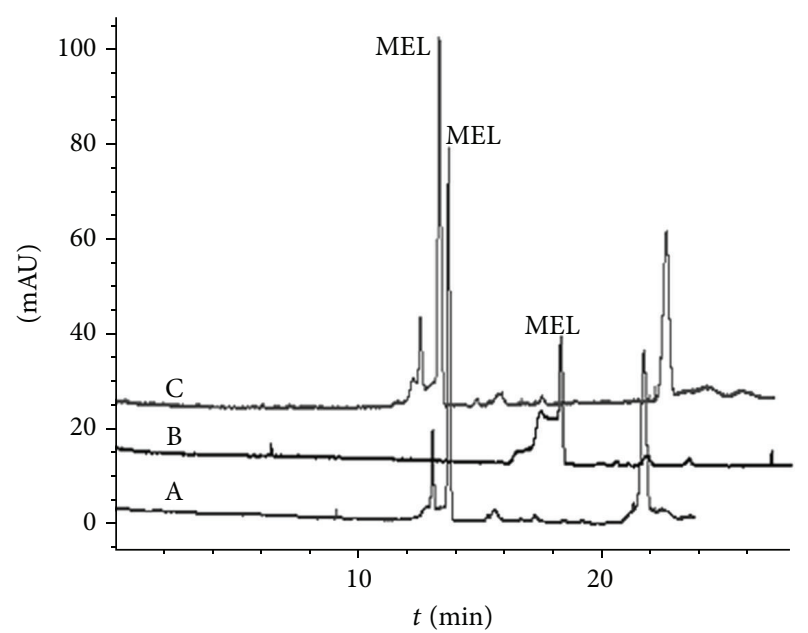

FIGURE 5: Electropherograms of real sample with/without the $\mathrm{NaOH}$ flushing step. (A) The first run of real sample with $\mathrm{NaOH}$ rinsing step; (B) the second run without $\mathrm{NaOH}$ rinsing step; and (C) the third run with $\mathrm{NaOH}$ re-rinsing. Condition: see Figure 3.

times and peak areas. Linearity range, using area as the function of the concentration, was obtained by adding different amount (final concentration of MEL ranged from $0.01 \mu \mathrm{mol} / \mathrm{L} \sim 50 \mu \mathrm{mol} / \mathrm{L}$ at ten concentration levels) of MEL directly into untreated real milk samples. Recovery was tested with adding known amount of MEL to real samples under two final concentration levels $(0.5 \mu \mathrm{mol} / \mathrm{L}$ and $5.0 \mu \mathrm{mol} / \mathrm{L})$. LOD was calculated at signal/noise $(\mathrm{S} / \mathrm{N})=3$. All the related data were shown in Table 1.

3.7. Assay of Real Milk Samples. The proposed method was applied to real milk samples. Separation and stacking results of two bands of milk products (YILI pure milk and WANGZAI reconstituted milk) were shown in Figure 6. It could be seen that MEL was well separated (from the interferent, $*$ in Figure 6 ), stacked, and detected in both tested milk samples using the established method within $20 \mathrm{~min}$. For example, the blank YILI sample (without adding MEL, Figure 6-(A)) showed no MEL peak even under stacking mode, while a low concentration of $0.5 \mu \mathrm{mol} / \mathrm{L}$ MEL could be easily detected (Figure 6-(C)) under stacking mode, with a $\sim 20$ folds enhancement of sensitivity compared with traditional CZE mode (Figure 6-(B)); for the assay of WANGZAI reconstituted milk (with adding MEL at a final concentration of $8.0 \mu \mathrm{mol} / \mathrm{L}$ ), similar phenomenon occurred (Figure 6(D)). All these proved that this method was applicable for analyzing MEL in milk products.

\section{Conclusion}

An ASS method for separation and determination of melamine in milk products was proposed. Under the optimum conditions, low concentration of melamine $(0.03 \mu \mathrm{mol} / \mathrm{L})$ in milk products could be successfully determined, which can cope with the maximum tolerable limits set worldwide for melamine and related compounds 
TABLE 1: Characters of established method.

\begin{tabular}{|c|c|c|c|}
\hline & Intraday & & Interday \\
\hline Time $(\mathrm{RSD} \%)(n=6)$ & 2.7 & & 4.8 \\
\hline Area $(\mathrm{RSD} \%)(n=7)$ & 2.2 & & 4.9 \\
\hline \multirow{2}{*}{ Recovery (\%) } & $0.5 \mu \mathrm{mol} / \mathrm{L}$ & & $5 \mu \mathrm{mol} / \mathrm{L}$ \\
\hline & $95 \%$ & & $112 \%$ \\
\hline Linearity range $(\mu \mathrm{mol} / \mathrm{L})$ & & $0.05 \sim 10$ & \\
\hline Function and $R^{2}$ & & Area $=12.679 \times$ Conc +4.7555 & $R^{2}=0.9907$ \\
\hline $\mathrm{LOD}(\mu \mathrm{mol} / \mathrm{L})$ & & 0.03 & \\
\hline
\end{tabular}

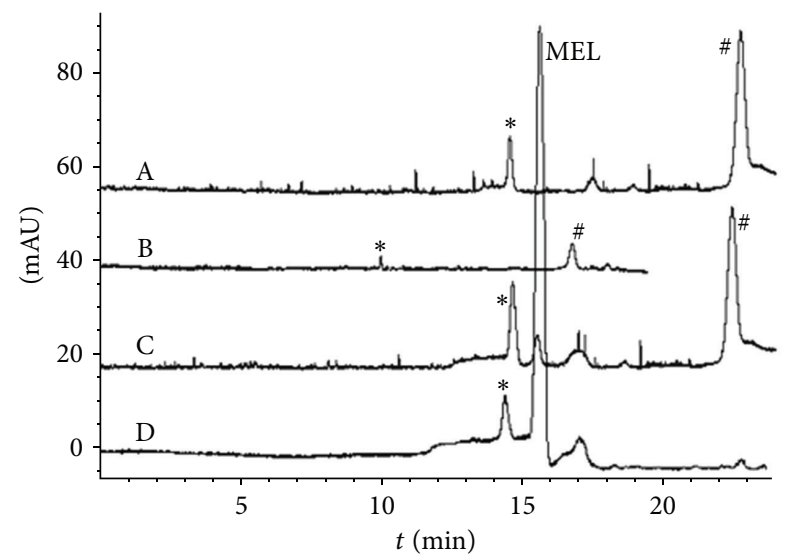

FIGURE 6: Electropherograms of real milk samples under optimized condition. (A)/(B)/(C) were samples from YILI pure milk; (D) was from WANGZAI reconstituted milk. Samples were treated with $60 \%$ acetonitrile (v/v) and were injected hydrodynamically at $50 \mathrm{mBar}$ for $40 \mathrm{~s}$. All samples also contained $8 \mathrm{mmol} / \mathrm{L} \mathrm{pH} 2.8$ phosphate solution and partial samples were added with MEL ((B)/(C) $0.5 \mu \mathrm{mol} / \mathrm{L}$; (D) $8 \mu \mathrm{mol} / \mathrm{L})$. Stacking was performed under $+10.0 \mathrm{kV}$ and results were detected at $200.0 \mathrm{~nm}$.

[26]. The established method also provided simple sample treatment steps, good reproducibility, and a wider linearity which indicated that it is suitable for routine assay of melamine in milk products.

\section{Conflict of Interests}

The authors do not have any possible conflict of interests.

\section{Acknowledgments}

This study is supported by Grant from the Fundamental Research Funds for the Central Universities (2011jdhz43), Grant from the Xian Jiao Tong University (xjj2009097), Grant from the National College Student Innovation Experimental Program in CHINA $(012008120015,2011028)$, and Grant from the National Natural Science Funds of CHINA (Grant no. 81101674).

\section{References}

[1] L. Choi, M. Y. Kwak, E. H. Kwak et al., "Comparative nephrotoxicitiy induced by melamine, cyanuric acid, or a mixture of both chemicals in either Sprague-Dawley rats or renal cell lines," Journal of Toxicology and Environmental Health A: Current Issues, vol. 73, no. 21-22, pp. 1407-1419, 2010.

[2] G. Li, S. Jiao, X. Yin, Y. Deng, X. Pang, and Y. Wang, "The risk of melamine-induced nephrolithiasis in young children starts at a lower intake level than recommended by the WHO," Pediatric Nephrology, vol. 25, no. 1, pp. 135-141, 2010.

[3] J. L. Dorne, D. R. Doerge, M. Vandenbroeck et al., "Recent advances in the risk assessment of melamine and cyanuric acid in animal feed," Toxicology and Applied Pharmacology, vol. 270, no. 3, pp. 218-229, 2013.

[4] Y. Wong and C. Mok, "A single analytical procedure for the simultaneous and confirmatory determination of melamine and related compounds in various food matrices by isotope dilution gas chromatography-mass spectrometry (ID-GCMS)," Analytical Methods, vol. 5, no. 9, pp. 2305-2314, 2013.

[5] S. Goscinny, V. Hanot, J. F. Halbardier, J. Y. Michelet, and J. van Loco, "Rapid analysis of melamine residue in milk, milk products, bakery goods and flour by ultra-performance liquid chromatography/tandem mass spectrometry: from food crisis to accreditation," Food Control, vol. 22, no. 2, pp. 226-230, 2011.

[6] V. D. L. M. Finete, M. M. Gouvea, F. F. Marques, and A. D. P. Netto, "Characterization of newfound natural luminescent properties of melamine, and development and validation of a method of high performance liquid chromatography with fluorescence detection for its determination in kitchen plastic ware," Talanta, vol. 123, pp. 128-134, 2014.

[7] Y. Zhang, S. Lin, P. Jiang et al., "Determination of melamine and cyromazine in milk by high performance liquid chromatography coupled with online solid-phase extraction using a novel cation-exchange restricted access material synthesized by surface initiated atom transfer radical polymerization," Journal of Chromatography A, vol. 1337, pp. 17-21, 2014.

[8] A. M. Giovannozzi, F. Rolle, M. Sega, M. C. Abete, D. Marchis, and A. M. Rossi, "Rapid and sensitive detection of melamine in milk with gold nanoparticles by Surface Enhanced Raman Scattering," Food Chemistry, vol. 159, pp. 250-256, 2014.

[9] Z. Z. Wang, D. J. Zhi, Y. Zhao et al., "Lateral flow test strip based on colloidal selenium immunoassay for rapid detection of melamine in milk, milk powder, and animal feed," International Journal of Nanomedicine, vol. 9, pp. 1699-1707, 2014.

[10] S. H. Baek, H. B. Lim, and H. S. Chun, "Detection of melamine in foods using terahertz time-domain spectroscopy," Journal of Agricultural and Food Chemistry, vol. 62, no. 24, pp. 5403-5407, 2014.

[11] C. Liao, Y. Chen, J. Chang, and J. Zen, "Single-run electrochemical determination of melamine in dairy products and pet foods," Journal of Agricultural and Food Chemistry, vol. 59, no. 18, pp. 9782-9787, 2011. 
[12] H. Sun, N. Liu, L. Wang, and Y. Wu, "Effective separation and simultaneous detection of cyromazine and melamine in food by capillary electrophoresis," Electrophoresis, vol. 31, no. 13, pp. 2236-2241, 2010.

[13] J. Xia, N. Zhou, Y. Liu, B. Chen, Y. Wu, and S. Yao, "Simultaneous determination of melamine and related compounds by capillary zone electrophoresis," Food Control, vol. 21, no. 6, pp. 912-918, 2010.

[14] M. Himmelsbach and T. D. Thanh Vo, "Determination of melamine impurities by capillary zone electrophoresis with UVand quadrupole time-of-flight mass spectrometric detection," Electrophoresis, vol. 35, no. 9, pp. 1362-1367, 2014.

[15] I. Tsai, S. Sun, H. Liao, S. Lin, and C. Kuo, "Rapid analysis of melamine in infant formula by sweeping-micellar electrokinetic chromatography," Journal of Chromatography A, vol. 1216, no. 47, pp. 8296-8303, 2009.

[16] Y. Jin, L. Meng, M. Li, and Z. Zhu, "Highly sensitive detection of melamine and its derivatives by capillary electrophoresis coupled with online preconcentration techniques," Electrophoresis, vol. 31, no. 23-24, pp. 3913-3920, 2010.

[17] X. Li, J. Hu, and H. Han, "Determination of cypromazine and its metabolite melamine in milk by cation-selective exhaustive injection and sweeping-capillary micellar electrokinetic chromatography," Journal of Separation Science, vol. 34, no. 3, pp. 323-330, 2011.

[18] W.-C. Wu, I. L. Tsai, S.-W. Sun et al., "Using sweepingmicellar electrokinetic chromatography to determine melamine in food," Food Chemistry, vol. 128, no. 3, pp. 783-789, 2011.

[19] Y. Kong, J. Yuan, and Z. Wang, "Assay of melamine in milk products with a Ph-Mediated stacking technique in capillary electrophoresis," Journal of Separation Science, vol. 37, no. 6, pp. 717-724, 2014.

[20] F. Foret, E. Szoko, and B. L. Karger, "On-column transient and coupled column isotachophoretic preconcentration of protein samples in capillary zone electrophoresis," Journal of Chromatography, vol. 608, no. 1-2, pp. 3-12, 1992.

[21] Z. K. Shihabi, "Sample matrix effects in capillary electrophoresis. II. Acetonitrile deproteinization," Journal of Chromatography, vol. 652, no. 2, pp. 471-475, 1993.

[22] Z. K. Shihabi, "Peptide stacking by acetonitrile-salt mixtures for capillary zone electrophoresis," Journal of Chromatography A, vol. 744, no. 1-2, pp. 231-240, 1996.

[23] Z. K. Shihabi, "Stacking of weakly cationic compounds by acetonitrile for capillary electrophoresis," Journal of Chromatography A, vol. 817, no. 1-2, pp. 25-30, 1998.

[24] Z. K. Shihabi, "Stacking and discontinuous buffers in capillary zone electrophoresis," Electrophoresis, vol. 21, no. 14, pp. 28722878, 2000.

[25] Y. Kong, N. Zheng, Z. Zhang, and R. Gao, “Optimization stacking by transient pseudo-isotachophoresis for capillary electrophoresis: example analysis of plasma glutathione," Journal of Chromatography B: Analytical Technologies in the Biomedical and Life Sciences, vol. 795, no. 1, pp. 9-15, 2003.

[26] "International experts limit melamine levels in food," http:// www.who.int/mediacentre/news/releases/2010/melamine_food _20100706/en/. 

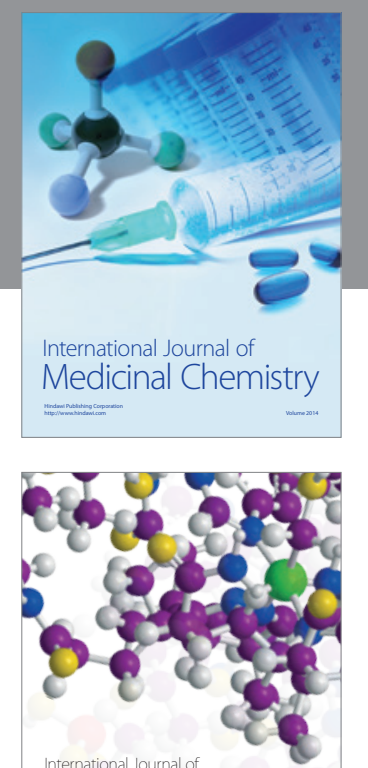

\section{Carbohydrate} Chemistry

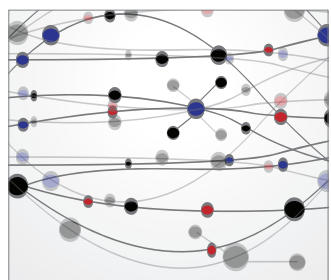

The Scientific World Journal
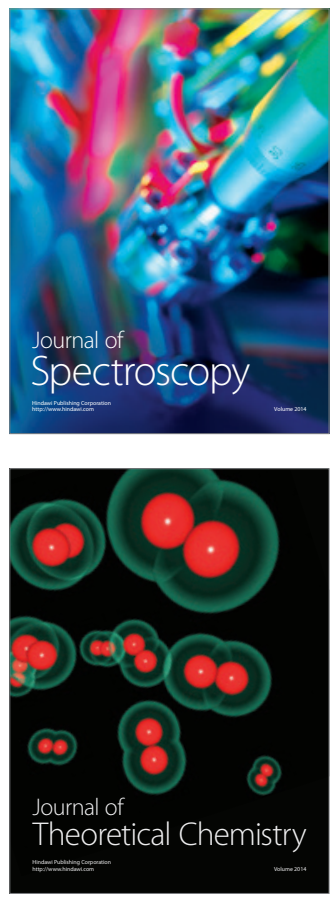
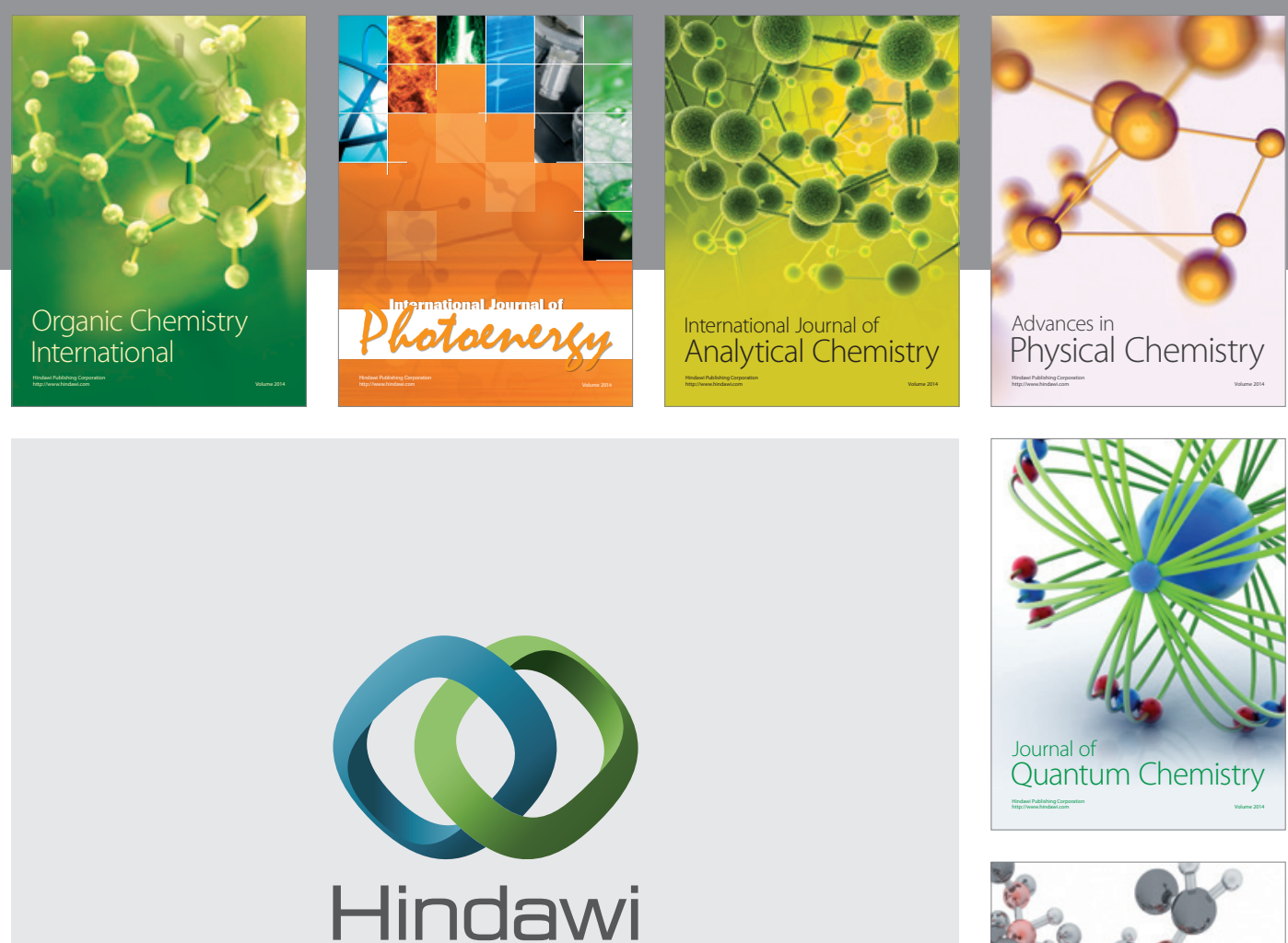

Submit your manuscripts at

http://www.hindawi.com

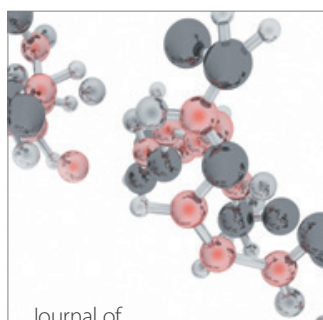

Analytical Methods

in Chemistry

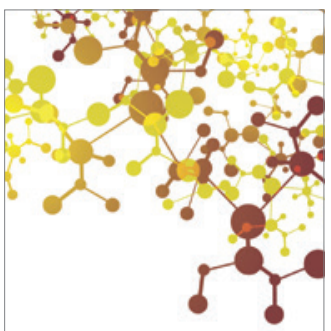

Journal of

Applied Chemistry

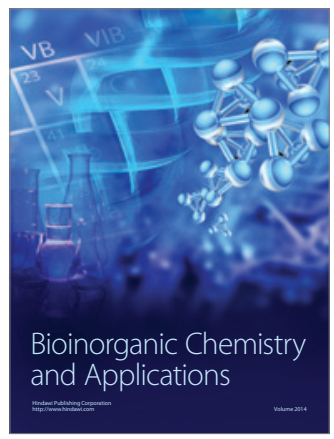

Inorganic Chemistry
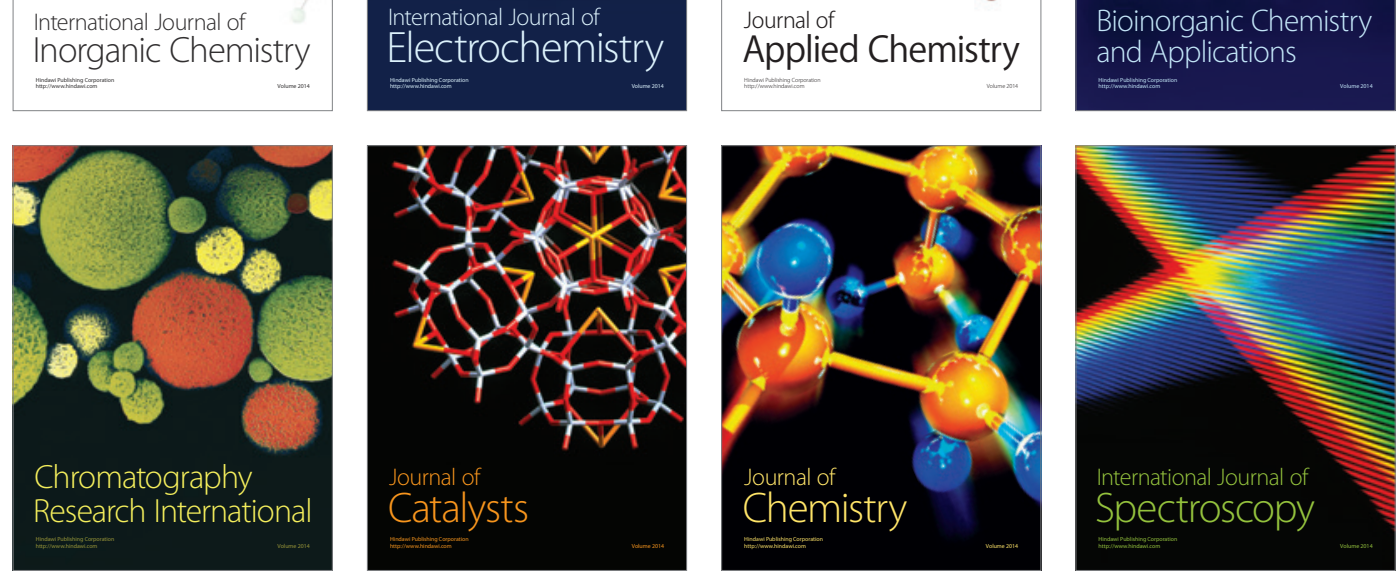